\title{
Inovação na hotelaria: a percepção desse processo através do olhar de gestores do Porto da Ilha Hotel (Florianópolis, Santa Catarina, Brasil)
}

\author{
Innovation in hospitality: the perception of innovation through the eyes of \\ managers of the Porto da Ilha Hotel (Florianópolis, Santa Catarina, Brasil)
}

\author{
Julia dos Santos Damasio (DAMASIO, J. dos S.) ${ }^{*}$ \\ Omar Abdel Muhdi Said Omar (OMAR, O. A. M. S.) ${ }^{* * *}$ \\ Micheline Gaia Hoffmann (HOFFMANN, G. M.) ${ }^{* * *}$
}

\begin{abstract}
RESUMO - As sociedades modernas estão impulsionadas pela economia baseada em serviços. Em Florianópolis (Santa Catarina, Brasil), a economia baseada em serviços, representa uma das principais atividades econômicas da cidade, que tem no Turismo e na Hotelaria um de seus maiores destaques. A Hotelaria enfrenta uma realidade de consumidores cada vez mais exigentes e aumento da concorrência, e por isso, tem o desafio de inovar a cada dia para conquistar novos clientes e manter o relacionamento estabelecido com os antigos. Para a melhor compreensão do fenômeno da inovação na Hotelaria, nesse artigo se apresenta o resultado da percepção do processo da inovação através do olhar de gestores de um Hotel Executivo do centro de Florianópolis. O método utilizado para a pesquisa foi o descritivo-exploratório com estudo de caso. Os dados foram colhidos com a realização de entrevistas. Os resultados demonstraram existir compreensão dos gestores sobre o processo de inovação como um todo, mas que na Hotelaria especificamente, ainda não relacionam com inovações de ruptura.
\end{abstract}

Palavras-chave: Inovação; Hotelaria; Competitividade.

ABSTRACT - Modern societies are driven by service-based economy. In Florianópolis, the service-based economy is one of the main economic activities of the city, which has in Tourism and Hospitality one of his greatest highlights. The Hospitality in particular, is facing a reality of increasingly demanding consumers and increasing competition, and therefore, has the challenge to innovate every day to win new customers and maintain the relationship established with the old ones. For better understanding the phenomenon of innovation in Hospitality, this article presents the

\footnotetext{
* Formação: Graduação em Administração com Habilitação em Comércio Exterior pelo Centro de Educação Superior (ÚNICA). Mestrado profissional em Administração pela Universidade do Estado de Santa Catarina (UDESC). Atividade profissional: Gerente de Operações do Porto da Ilha Hotel. Endereço físico para correspondência: Rua: Dom Jaime Câmara, 43. CEP: 88015-120 - Florianópolis/SC - Brasil. Email: judamasio0@hotmail.com

** Formação: Graduação em Sistemas de Informação pela Universidade Federal de Santa Catarina (UFSC), Mestrado profissional em Administração pela Universidade do Estado de Santa Catarina (UDESC). Doutorando do Programa de Pós-Graduação em Engenharia e Gestão do Conhecimento da Universidade Federal de Santa Catarina (UFSC). Endereço físico para correspondência: Campus Reitor João David Ferreira Lima. CEP: 88040-900 - Florianópolis/SC - Brasil. Email: omarx02@ gmail.com

Formação: Graduação em Administração pela Universidade do Estado de Santa Catarina (UDESC/ESAG), Mestrado e Doutorado em Engenharia de Produção pela Universidade Federal de Santa Catarina (UFSC). Atividade profissional: Professora da Universidade do Estado de Santa Catarina (UDESC). Endereço físico para correspondência: Av. Madre Benvenuta, 2037. CEP: 88035-001 Florianópolis/SC - Brasil. Email: michelinegaia@gmail.com
} 
perception of the innovation process through the eyes of managers from an Executive Hotel in downtown Florianópolis. The method used to the research was descriptive and exploratory with case study. Data were collected through interviews. The results show managers seems to understand the innovation process as a whole, but however in Hospitality specifically, still don't relate innovation to disruptive innovations. 2013.

Key words: Innovation; Hospitality; Competitive Edge. 


\section{INTRODUÇÃO}

As sociedades modernas estão impulsionadas pela economia baseada em serviços. Segundo dados do Instituto Brasileiro de Geografia e Estatística - (IBGE, 2008), 60\% do Produto Interno Bruto - PIB no Brasil provinha dos serviços; que respondia por $70 \%$ da mão de obra empregada no país. Em Florianópolis, representa uma das principais atividades econômicas e tem no Turismo e na Hotelaria um de seus grandes destaques. (DAMASIO, 2014).

Uma vez constatada a importância do setor de serviços na economia brasileira e mais especificamente na economia de Florianópolis, pode-se perceber a grande relevância desse tema. Dentre os serviços em expansão, a Hotelaria enfrenta uma realidade de consumidores cada vez mais exigentes e aumento da concorrência; e tem o desafio de se inovar a cada dia para conquistar novos clientes e manter o relacionamento com os antigos. Com relação a esse aspecto, Gorni, Dreher e Machado (2009) ressaltam que investir em inovações pode proporcionar às organizações as condições fundamentais para que se mantenham no mercado e se mostrem competitivas.

No passado, os hotéis eram caracterizados como simples meios de hospedagem, em que a missão do empreendimento era dispor de um quarto confortável com o oferecimento dos serviços básicos. Posteriormente, para que uma empresa pudesse se destacar em meio à concorrência tornou-se necessário ser cada vez mais inovadora e atender as necessidades de seus hóspedes.

Para Silva (2012) uma empresa inovadora possui uma gama maior de produtos oferecidos e está sempre aplicando melhorias nos produtos já dispostos no mercado. Como a hotelaria vende um produto misto (bens + serviços), prezar por inovações é planejar a continuidade de uma empresa e garantir sua competitividade diante dos concorrentes (PORTAL DA EDUCAÇÃO, 2012).

Embora a inovação seja um processo bastante difundido na indústria, não o é no setor de serviços. De acordo com Graeml (2007), as possibilidades de inovações no terceiro setor têm sido tema negligenciado pela maioria dos pesquisadores. Esse é um dos aspectos que motivaram a escolha do tema desta pesquisa, com a finalidade de contribuir com estudos que visem entender com maior profundidade o processo de inovação em serviços e mais especificamente na Hotelaria de Florianópolis. 
Assim, pensando que o objetivo primordial dos serviços é o atendimento às diferentes demandas dos usuários, de modo a supri-las totalmente, cabe aos gestores das organizações hoteleiras desenvolverem estratégias capazes de facilitar tal processo, e a inovação pode fazer parte da construção das mesmas.

Então, considerando o crescimento da participação dos serviços na economia, a importância da inovação para a competitividade nesse setor, e o foco na "indústria" hoteleira, o objetivo deste estudo foi o de compreender: Como os gestores do Porto da Ilha Hotel percebiam o processo da inovação na Hotelaria?

\section{REFERENCIAL TEÓRICO}

Para a consolidação da pesquisa, entendeu-se como fundamental trazer informações do setor ao qual a hotelaria está inserida como forma de localizá-la neste cenário, além de compreender os conceitos inerentes a Inovação, Hotelaria e Inovação Hoteleira, de modo a melhor visualizar o contexto que se identificará no campo.

\subsection{INOVAÇÃO NO SETOR DE SERVIÇOS}

O setor de serviços exerce papel crescente na atividade econômica nacional e tem grande destaque na economia de Florianópolis. Este setor apresenta inúmeras diferenças frente aos bens e demanda dos gestores que administrem seus negócios de forma diferente às indústrias.

De acordo com Escauriaza, Subirana e Torres (2001), o conceito de serviços é ambíguo e heterogêneo, pois inclui diversas atividades econômicas. $\mathrm{Na}$ visão dos autores Hoffman e Bateson (2003) a maioria dessas diferenças é atribuída principalmente a quatro características: intangibilidade, inseparabilidade, heterogeneidade e perecibilidade. Serviços são caracterizados como intangíveis porque são desempenhos ou ações, e não objetos, ou seja, não podem ser tocados; há inseparabilidade entre produção e consumo, já que os serviços são vendidos primeiro e então produzidos e consumidos simultaneamente. A heterogeneidade, diz respeito ao potencial para o desempenho do serviço variar de uma transação de serviço para a 
seguinte; como os serviços são produzidos por pessoas, a variabilidade é inerente ao processo. E finalmente, a perecibilidade quer dizer que os serviços não podem ser estocados; em um Hotel, por exemplo, se o apartamento não é vendido em um dia, não pode mais ser vendido no seguinte.

Shostack (1982), explica que serviços não são "coisas", portanto, devem ser percebidos como processos ao invés de objetos. A autora sugere dois caminhos para a descrição do processo serviço, um de acordo com as etapas e sequências que constituem o processo (complexidade do processo) e outra em consonância com a variabilidade dessas etapas e sequências (diversidade).

Essas características fazem com que inovar e satisfazer clientes torne-se desafio de gestores, já que os serviços são experimentados e sentidos, e os julgamentos dos clientes sobre eles tendem a ser mais subjetivos do que objetivos. Essa seria a razão segundo Cardellino e Finch (2006), pela qual as pesquisas sobre inovação concentramse muito mais em organizações de bens do que em de serviços.

Com o intuito de satisfazer e fidelizar clientes, as organizações que prestam serviços seguem em busca da inovação. Na literatura sobre inovação, Schumpeter (1985) foi um dos primeiros economistas a analisar a importância econômica da inovação. Em sua definição, o autor destaca a relação estreita entre inovação e invento, de forma que as inovações implicam o desenvolvimento de inventos, institucionalizando novos métodos de produção ou introduzindo novos produtos ou serviços no mercado. Na visão de Christensen (2000) a inovação acontece quando alguma das tecnologias de uma organização muda; entende-se por inovação de ruptura aquela que traz ao mercado algo muito diferente do que está disponível até então; e por inovação incremental aquelas que têm em comum o efeito de melhorar o desempenho de produtos já estabelecidos.

Para Gadrey, Gallouj e Weinstein (1994), as teorias de inovação com base e observação na indústria são inadequadas para explicar as formas de inovações em serviços. Baseados em evidências empíricas, Sundbo e Gallouj (1998) apresentaram a seguinte taxonomia para classificar os tipos de inovação observados no setor de serviços, conforme podem ser identificados abaixo:

- Inovação de produto (serviço): refere-se à criação e ao fornecimento de um novo serviço, por exemplo, uma nova linha de financiamento, um novo tipo de seguro; 
- Inovação de processo: relacionada com a modificação de procedimentos prescritos para a elaboração/produção de um serviço ou nos procedimentos de atendimento do usuário/cliente e de entrega do serviço;

- Inovação gerencial: relacionada com a introdução de novas técnicas de planejamento, gerenciamento de processos, adoção de indicadores e etc.;

- Inovação de mercado: relacionada com a descoberta de novos mercados, com a identificação de nichos em um mesmo mercado ou, ainda, com a mudança de comportamento da organização no mercado em que ela está inserida;

- Inovação ad hoc: resultado de um processo de resolução de problemas do usuário por meio da coprodução. A intensidade da relação usuário/produtor em serviços permite considerar o usuário (ou cliente) como uma importante fonte de formação de capacidades. São exemplos as empresas de consultoria.

Para esses autores, a inovação em serviços geralmente acarreta em mudanças de elementos do processo produtivo e do produto simultaneamente, já que não se pode separar a produção do consumo em um serviço.

De forma a contribuir para a taxonomia de inovação em serviços, Hauknes (1998) salienta que a intensidade da relação usuário/produto em serviços pressupõe considerar o usuário (cliente) como uma importante fonte de formação de capacidades.

De acordo com Sundbo e Gallouj (1998), as inovações podem ser dirigidas por forças internas ou externas. As externas estariam relacionadas às trajetórias institucionais, tecnológicas, gerenciais e profissionais que influenciam determinados serviços, além do relacionamento com fornecedores, competidores e especialmente clientes. Já as internas, são estabelecidas pela existência ou não de estruturas formais dedicadas à inovação, pelo envolvimento dos trabalhadores do processo de mudança e pela integração do processo de inovação ao planejamento estratégico da organização. As diferentes formas que essas se combinam, determinará o padrão de inovação.

Ainda segundo Sundbo e Gallouj (1998), as inovações em empresas de serviço são em sua maioria incrementais, constituídas de pequenos ajustes e com facilidade imitadas por seus competidores. Poucas empresas de serviços possuem um departamento de pesquisa e desenvolvimento específico para a inovação, ou mesmo incentivam seus funcionários a que inovem em suas práticas diárias. Para Sundbo e Gallouj (1998), as empresas de maior porte e as que se internacionalizam são 
consideradas mais inovadoras. De qualquer forma, as empresas menores também buscam a inovação como estratégia, para que através dela se mantenham competitivas no mercado.

Para Klement (2007) a inovação deve visar ao aumento da qualidade, diminuição de custos do ciclo de vida do produto e redução do tempo de desenvolvimento, sendo que uma das características é o foco nas necessidades do consumidor. Dessa forma, através da inovação, as empresas buscam a atender às exigências de tempo de resposta dos consumidores, assim como aumentar sua produtividade, melhorar a qualidade e, principalmente, diminuir o ciclo de projetos, no intuito de se manterem à frente da concorrência.

\subsection{A HOTELARIA NO CONTEXTO DA INOVAÇÃO}

Os hotéis desempenham um papel importante na maioria dos países, na medida em que oferecem instalações para transações de negócios, reuniões e conferências, recreação e entretenimento. De acordo com Powers e Barrows (2004), em muitas regiões, os hotéis se tornam atrações importantes para os visitantes, contribuindo de forma significativa para a economia local, tanto direta quanto indiretamente. Os hotéis se caracterizam ainda por serem grandes empregadores de mão de obra.

Antigamente as empresas hoteleiras eram negócios pequenos e familiares, que cresceram junto com o setor de turismo. Gonzáles, Gallego e Zamora (2009) destacaram que se está deixando para trás o período pós industrial dos anos setenta, e se firmando a era dos serviços e das novas gerações da eletrônica.

O Ministério do Turismo define hotel como um estabelecimento com serviço de recepção, alojamento temporário, com ou sem alimentação, ofertados em unidades individuais e de uso exclusivo do hóspede, mediante cobrança de diária (MTUR, 2014).

Duarte (2003) disserta sobre o histórico das classificações hoteleiras e afirma que a primeira foi implantada no Brasil sobre a administração do Instituto Brasileiro de Turismo (EMBRATUR), no fim da década de 70, como forma de ordenar o setor. Na época, foi elaborada uma planilha de avaliação, e a classificação era cedida de acordo com o cumprimento aos requisitos propostos. Estes requisitos abrangiam três áreas: os aspectos construtivos, instalações e equipamentos e serviços. 
O sistema de classificação vigente é o - SBClass - Sistema de Classificação de Meios de Hospedagem, que foi apresentado em 2010, e sancionado em 2011 pelo MTur, através da pela portaria $n^{\circ}$ 100, de 16 de Junho de 2011 (MTUR, 2011). Está baseado em três grandes requisitos: infraestrutura, serviços e sustentabilidade, que são divididos em mandatórios (ou seja, de cumprimento obrigatório pelo meio de hospedagem) e eletivos (ou seja, de livre escolha do meio de hospedagem, tendo como base uma lista pré-definida) para a obtenção de estrelas. Para cada estrela adicional, o hotel deve atender a uma série de requisitos que diferenciam as categorias entre si.

O mercado de meios de hospedagem é bastante variado e criativo, tendo corno forte característica a criação de produtos para os mais variados públicos e possibilidades econômicas, marcando a atividade da hospitalidade por sua variedade e complexidade.

De acordo com Beni (2002), um hotel se diferencia de outros empreendimentos no que tange à interação entre cliente e funcionários, promovendo uma grande importância ao atendimento ao cliente.

Para Santos (2005), a vocação de Florianópolis para a hoteleira começou como uma necessidade de atender aos trabalhadores das atividades portuárias na virada do século XVIII para o XIX. Desde então e com muitas mudanças, é um mercado que não para de se desenvolver. Ainda de acordo com Santos (2005), embora até 1990 o turismo em Florianópolis tenha sido canalizado para as praias, o mercado turístico da região passou a sofrer grandes alterações a partir de 1998, com a intensificação dos fluxos turísticos de negócios e eventos que promoveram modificações significativas na hotelaria, principalmente aquela localizada no núcleo central da cidade. É nesse contexto que se inaugura em Florianópolis o Porto da Ilha Hotel, empresa em que a pesquisa foi realizada. (DAMASIO, 2014).

Sempre em busca da satisfação dos clientes, é uma preocupação constante do Porto da Ilha Hotel alcançar a excelência em tudo aquilo que oferece a seus hóspedes. (DAMASIO, 2014). E a inovação segundo Gorni, Dreher e Machado (2009) torna-se imprescindível ao desenvolvimento da atividade turística, em que as organizações envolvidas objetivam a melhora na qualidade dos serviços e maior lucro.

O mercado consumidor passou a exigir um tratamento individualizado, fazendo com que as empresas, entre outras medidas, diminuíssem o ciclo de desenvolvimento de novos produtos. Para conseguir isso, segundo Fine (1999), as empresas têm adotado as 
mais variadas estratégias para o processo de inovação, buscando escolher o projeto certo e manter-se em vantagem competitiva, uma vez que esta é temporária.

De acordo com Gonzáles, Gallego e Zamora (2009), as transformações nas empresas hoteleiras têm sido constantes; novos sistemas de comercialização e reservas, contratação de mão-de-obra terceirizada, incorporação da informática à hotelaria, são exemplos claros das mudanças e inovações que ocorreram nas empresas hoteleiras.

O surgimento, propagação e popularização da Internet é um dos principais aspectos a ser destacado diante das transformações no ramo da Hotelaria. A internet trouxe a evolução e surgimento de canais de comercialização de hospedagem, com venda por internet, o que facilitou por um lado o acesso a informação por parte dos hóspedes, mas que por outro lado criou uma guerra por tarifas. E só quem consegue se diferenciar utilizando as novas ferramentas de vendas e divulgação do Hotel é que poderá se beneficiar de seus pontos positivos. (DAMASIO, 2014).

Além disso, outra mudança trazida pelo advento da internet, nos serviços prestados pelos hotéis é a capacidade de divulgação que os hóspedes têm de informações em sites de comercialização e avaliação de Hotéis, publicando comentários e fotos rapidamente na rede; o que faz com que os serviços tenham que ser prestados com qualidade e novidade constantes. (DAMASIO, 2014)

Diante dessas novas características de mercado, que a Hotelaria vêm enfrentando, Marín (2004) ${ }^{1}$ apud Gorni, Dreher e Machado (2009), defende que, para se manter e atender às exigências dos clientes, precisam adaptar suas estratégias às novas regras de mercado, como investimento na renovação tecnológica que dê suporte ao negócio e atenda às suas necessidades atuais.

\section{METODOLOGIA}

A metodologia constitui um traçado indispensável na investigação dos fatos ou da pesquisa científica. De acordo com Silveira (2004) ela é responsável por examinar e refletir sistematicamente o melhor caminho que pode conduzir um trabalho científico ao

\footnotetext{
${ }^{1}$ MARÍN, A. Tecnologia da informação nas agências de viagens: em busca da produtividade e do valor agregado. São Paulo: Aleph, 2004.
} 
êxito, além de conferir-lhe segurança na explanação e obtenção dos resultados garantindo a legitimidade do saber obtido.

Baseando-se em Vergara (2000), a presente pesquisa caracterizou-se por ser exploratória-descritiva quanto aos fins e ainda um estudo de caso realizado em campo; quanto aos meios, na pesquisa se adota uma abordagem qualitativa, considerando os funcionários do hotel como fonte direta dos dados, conseguidos através de entrevista, e quantitativa para auxiliar na análise dos dados e definição do perfil dos gestores.

Na pesquisa exploratória, conforme Vergara (2000), o intuito é aproximar-se do tema com o objetivo de criar uma relação de familiaridade com um fenômeno ou fato. Já na pesquisa descritiva, procura-se obter informações para descrever características de um fenômeno, no caso deste estudo, a inovação. Vergara (2000) considera que uma pesquisa é descritiva quando expõe características de determinada população e fenômeno, mas que não tem compromisso de explicá-los.

No que se refere à pesquisa qualitativa reforça-se o entendimento de Godoy (2005) ao considerar o ambiente como fonte direta dos dados e ele próprio como instrumento chave; focando o processo e não o resultado, tendo como maior preocupação a interpretação de fenômenos.

Os objetivos da pesquisa foram alcançados através de um estudo de caso realizado no Porto da Ilha Hotel. Um estudo de caso conforme Gil (1991) é um estudo profundo e exaustivo que permite um amplo e detalhado conhecimento do que se está estudando.

Utilizaram-se técnicas quantitativas para definir o perfil dos gestores e qualitativa para a definição da percepção do processo da Inovação segundo o viés dos gestores do Porto da Ilha. A técnica utilizada para a coleta de dados foi a entrevista e a análise e interpretação de dados se deu de acordo com a técnica de análise de conteúdo.

Para obter a percepção do processo da inovação dos serviços em Hotelaria pelo viés dos gestores do Porto da Ilha, foram entrevistados os seguintes atores:

- Gerente Comercial: responsável pelas políticas de comercialização do Hotel, estratégias de divulgação, política tarifária e ainda área de reservas do Hotel;

- Gerente Operacional: responsável pela operação das equipes do Hotel visando a satisfação dos hóspedes; 
- Supervisor Comercial: responsável por manter as políticas de comercialização do Hotel, controlar canais de venda on line, reservas e eventos.

- Supervisor da Recepção: responsável por toda operação da Recepção;

- Chefe de Cozinha: responsável pela equipe da Cozinha em todas as suas atribuições;

- Governantas: sendo duas no Hotel e responsáveis pela organização e limpeza dos apartamentos e áreas sociais do Hotel assim como da Lavanderia que é própria.

As perguntas da entrevista foram elaboradas com base no questionário utilizado por Gorni, Dreher e Machado (2009), que se inspiraram no questionário fechado de Zhuang (1995).

Após a coleta e análise dos dados, categorias de análise foram formuladas através da análise de conteúdo. A análise de conteúdo possibilitou o conhecimento da percepção do processo da inovação para gestores do Porto da Ilha Hotel.

\subsection{O HOTEL PORTO DA ILHA}

Fundado em 1998, o Porto da Ilha Hotel encontra-se no centro da cidade de Florianópolis. (DAMASIO, 2014). Na mesma fonte consta que é uma empresa familiar que tem 55 funcionários e conta com a participação dos donos na sua administração desde o seu início. Além disso, que foi projetado para atender ao exigente mercado empresarial, sua localização é privilegiada, pois permite rápido acesso a diversos pontos da cidade.

De acordo com informações postadas no site do Porto da Ilha Hotel, o mesmo conta com 80 apartamentos divididos em Standard, Luxo, Superior e Premium. Todos cuidadosamente decorados e equipados com ar condicionado Split quente e frio, amenities, mesa de trabalho, frigobar, telefone com discagem direta, televisão LCD por cabo, e internet wifi cortesia (PORTO DA ILHA, 2014).

\section{ANÁLISE E DISCUSSÃO DOS RESULTADOS}

A análise dos resultados demonstra a realidade da percepção dos gestores à cerca do processo de inovação em um hotel executivo localizado no centro de Florianópolis, o 
Porto da Ilha. Para tanto, foram elaborados quadros que em que se demonstram as principais questões levantadas com base na coleta de dados. Os quadros apresentam as variáveis analisadas por números absolutos.

Como o enfoque da pesquisa foi estabelecido em analisar a percepção dos gestores que estavam atuando no Porto da Ilha Hotel, acerca do processo de inovação; torna-se relevante observar o perfil desses indivíduos, demonstrado por meio do Quadro 1.

QUADRO 1 - PERFIL DOS RESPONDENTES

\begin{tabular}{|c|c|c|c|c|c|c|c|}
\hline Cargo & Citações & Idade & Citações & Formação & Citações & Tempo de Casa & Citações \\
\hline Gerente & 2 & de 20 & 2 & 2 grau & 2 & de 1 a 3 anos & 1 \\
\hline Comercial & 1 & a 40 & 5 & 3 grau & 1 & de 3 a 5 anos & 3 \\
\hline $\begin{array}{l}\text { Supervisor } \\
\text { de Recepção } \\
\text { Chefe de }\end{array}$ & 1 & & & Especialização & 4 & de 5 a 10 anos & 2 \\
\hline Cozinha & 1 & & & & & de 10 a 15 anos & 1 \\
\hline Governanta & 2 & & & & & & \\
\hline
\end{tabular}

Fonte: Pesquisa de campo, 2013.

Com relação a ocupação profissional, observou-se que, por serem líderes, todos tinham cargos de grande responsabilidade em suas áreas de atuação e que o único setor em que havia dois cargos do topo da hierarquia é o da Governança, com duas Governantas.

Outro dado importante disse respeito ao nível de escolaridade e tempo de casa dos respondentes. Mais da metade dos entrevistados, quatro deles, apontou possuir pósgraduação em nível de especialização. Quanto ao tempo de casa, a permanência também foi considerada alta, já que três dos respondentes comentaram estar de 3 a 5 anos trabalhando no Porto da Ilha; chamando ainda atenção, o fato de uma das pessoas trabalhar de 10 a 15 anos na empresa. O elevado índice de permanência demonstrou a capacidade da empresa em manter suas lideranças.

Os próximos itens da análise referem-se a percepção das lideranças entrevistadas sobre o processo de inovação na Hotelaria. A primeira pergunta realizada aos líderes foi: O que você entende por inovação? No quadro 2, foram sintetizadas as respostas dos entrevistados em categorias. 
QUADRO 2 - CONCEITO DE INOVAÇÃO

\begin{tabular}{|lc|}
\hline \multicolumn{1}{|c|}{ Conceito } & Citações \\
\hline Invenção de algo novo & 1 \\
Criar novos produtos & 4 \\
Criar novos métodos e serviços & 2 \\
Trazer novidade & 2 \\
Renovar ideias & 2 \\
Mudança & 2 \\
Melhorar produtos já existentes & 4 \\
Novas estratégias & 1 \\
Fazer mais com menos recursos & 1 \\
\hline Fonte: Pesquisa de campo, 2013.
\end{tabular}

De acordo com os dados expostos no quadro dois, foi possível afirmar que os gestores respondentes demonstraram compreender o conceito de inovação. Sendo que, as três primeiras categorias estabelecidas após entrevista, mostraram que os gestores perceberam a inovação como algo novo, sete das citações. Na percepção deles, a inovação estaria relacionada com a invenção; estariam também relacionadas ao que Christensen (2000) definiu como inovação de ruptura, que é aquela que traz ao mercado algo muito diferente do que está disponível até então.

As próximas categorias definidas: "trazer novidade", "renovar ideias", "mudança" e "melhorar produtos existentes", também ajudaram a definir o conceito de inovação; o incremental, proposto por Christensen (2000) como aquelas que têm em comum o efeito de melhorar o desempenho de produtos já estabelecidos; e defendido por Sundbo e Gallouj (1998) como as mais frequentes em setores de serviços. As quatro categorias juntas somaram dez citações.

O menor número de citações encontrado sobre o conceito de inovação, disse respeito as categorias "novas estratégias" e "fazer mais com menos recursos", com apenas duas das citações. A criação de novas estratégias estaria ligada a uma inovação gerencial, e fazer mais com menos recursos, a necessidade da empresa se manter competitiva e eficaz no mercado em que está inserida.

$\mathrm{O}$ segundo questionamento feito aos respondentes foi: Por que motivo as empresas inovam? No quadro 3 as respostas foram sintetizadas em categorias e serão apresentadas abaixo. 
QUADRO 3 - PORQUE AS EMPRESAS INOVAM?

\begin{tabular}{|lc|}
\hline \multicolumn{1}{|c|}{ Conceito } & Citações \\
\hline Para lidar com a concorrência. & 4 \\
Para atingir diferentes públicos / segmentos. & 1 \\
Por estratégia competitiva. & 1 \\
Para otimizar resultados com menos recursos. & 2 \\
Para manter posicionamento no mercado. & 3 \\
Para conquistar clientes. & 2 \\
Para garantir a saúde da empresa. & 1 \\
\hline
\end{tabular}

Fonte: Pesquisa de campo, 2013.

Analisando os dados, foi possível verificar a preocupação dos gestores com o ambiente externo e interno aos quais estavam inseridos. Quanto ao ambiente externo, pôde-se perceber essa preocupação nas seguintes categorias: "para lidar com a concorrência", "para manter posicionamento no mercado", "para conquistar clientes" e "para atingir diferentes públicos segmentos", somando 10 citações. Com relação ao ambiente interno, as categorias foram: "por estratégia competitiva", "para otimizar resultados com menos recursos" e "para garantir a saúde da empresa" com o total de 4 das citações.

Esses dados corroboram a discussão de Sundbo e Gallouj (1998), que afirmam que as inovações podem ser dirigidas por forças internas ou externas e que ambas se combinam para determinar o padrão de inovação.

Constatado que os gestores entediam o que seria inovação e porque motivo as empresas inovavam, foram questionados sobre características de uma pessoa inovadora conforme se demonstra no quadro 4.

\section{QUADRO 4 - CARACTERÍSTICAS DE UMA PESSOA INOVADORA}

\begin{tabular}{|lc|}
\hline \multicolumn{1}{|c|}{ Conceito } & Citações \\
\hline Buscar conhecimento. & 2 \\
Estar atualizada. & 1 \\
Querer mudar/estar disposto a mudar. & 5 \\
Saber ouvir. & 2 \\
Ter mente ágil. & 1 \\
Saber expressar suas ideias. & 2 \\
Ser criativa. & 1 \\
Saber colocar ideias em prática. & 4 \\
Buscar novidades no mercado. & 2 \\
\hline
\end{tabular}

Fonte: Pesquisa de campo, 2013. 
Chamou atenção o fato de na opinião dos respondentes, com 5 citações, as características de uma pessoa inovadora, estarem ligadas a capacidade e disponibilidade para a mudança. Os entrevistados entenderam que não só a inovação pressupunha mudança, como a pessoa inovadora teria que carregar consigo a capacidade para tal. Outras características pessoais de uma pessoa inovadora parecem estar voltadas a comunicação, quando em 8 das citações, os gestores indicaram que a pessoa precisava "saber expressar suas ideias", "saber colocar ideias em prática" e "saber ouvir".

Ainda de acordo com a opinião dos gestores do Porto da Ilha, seriam características de uma pessoa inovadora: "ser criativa" e "ter mente ágil" com 2 citações. As demais características pareceram estar ligadas a iniciativa e preocupação com o ambiente externo, com as seguintes categorias: "buscar conhecimento", "estar atualizada" e "buscar novidades no mercado", somando 5 citações.

Os dados referentes à opinião dos respondentes sobre o processo de inovação realizado especificamente na Hotelaria são demonstrados por meio do quadro 5.

\section{QUADRO 5 - INOVAÇÃO NA HOTELARIA}

\begin{tabular}{|lc|}
\hline \multicolumn{1}{|c|}{ Conceito } & Citações \\
\hline Utilizar novas técnicas voltadas a satisfação do hóspede. & 1 \\
Dar atendimento 5 estrelas com recursos ao alcance. & 2 \\
Trazer novos métodos a forma como as coisas são feitas. & 2 \\
Trazer melhores serviços ao cliente. & 4 \\
Buscar excelência na prestação de serviços. & 4 \\
Inovar em serviços. & 2 \\
Ser diferente dos demais hotéis. & 2 \\
& \\
Estar qualificado e atualizado no mercado de bens e serviço. & 1 \\
Superar as expectativas dos clientes. & 1 \\
\hline
\end{tabular}

Fonte: Pesquisa de campo, 2013.

Na maior parte das respostas dos gestores do Porto da Ilha, considerou-se ter ficado clara a importância da inovação como estratégia para atender ainda melhor aos hóspedes e satisfazer suas expectativas. As seguintes categorias: "utilizar novas técnicas voltadas a satisfação do hóspede", "dar atendimento 5 estrelas com recursos ao alcance", "trazer melhores serviços ao cliente", "buscar excelência na prestação de serviço" e "superar as expectativas dos clientes" somando 12 citações para esse questionamento sintetizaram o que os gestores entenderam por inovação na Hotelaria. 
Essas categorias, segundo o modelo de Sundbo e Gallouj (1998) estariam ligadas as inovações definidas pelos autores como de processo, focando no cliente e no atendimento como grande diferencial para permanecerem de modo competitivo no mercado.

Os demais aspectos indicados como inovação na Hotelaria foram: "trazer novos métodos a forma como as coisas são feitas" e "inovar em serviços" somando 4 citações; indicando novamente a ideia da inovação como possibilidade para se melhorar algo; a ideia de inovação incremental definida por Christensen (2000) e também por Sundbo e Gallouj (1998) como inovação de processo.

As últimas categorias destacadas como motivo para a inovação demonstraram uma preocupação com a concorrência; sendo elas: "ser diferente dos demais hotéis" e "estar qualificado e atualizado no mercado de bens e serviço" com 3 citações. Os respondentes demonstraram acreditar que a inovação poderia ser utilizada positivamente para acompanhar e até mesmo superar a concorrência. No entanto, não pareceram ter clareza da possibilidade de inovar através de inovações definidas por Sundbo e Gallouj (1998) como de produto (serviço), com a capacidade de pensar a inovação para a criação de um novo produto ou serviço totalmente novo na Hotelaria, ou ainda como uma inovação de ruptura definida por Christensen (2000).

\section{CONCLUSÃO}

O mercado de serviços turísticos no Brasil e, mais especificamente, em Santa Catarina e em Florianópolis tem crescido de forma expressiva. Estar alinhado a esse crescimento e oferecer serviços inovadores tornou-se pressuposto básico para qualquer empreendimento turístico.

O termo inovação liga-se a um contexto de mudança, de competição, de capacidade produtiva e de diferenciação. Nos estudos organizacionais, o tema permeia discussões e abre campos para atuações em diferentes níveis. Sendo assim, antes de praticar a inovação, torna-se pertinente procurar identificar qual a percepção de inovação que os gestores têm. 
Neste trabalho buscou-se identificar como os gestores percebiam o processo de inovação na hotelaria, e mais especificamente em uma unidade hoteleira de Florianópolis. A percepção dos gestores foi acessada através de entrevista.

Com a análise dos dados, foi possível verificar que os gestores do Hotel Porto da Ilha entenderam o que seria o processo de inovação e a importância que deram para esse tema. Essa constatação pode ser atribuída ao alto nível de escolaridade e a possibilidade de já terem discutido essa temática aliada à competitividade nos cursos de Graduação e Pós Graduação realizados por eles.

No entanto, quando questionados sobre inovações na hotelaria, pareceram corroborar com a ideia de Sundbo e Gallouj (1998), de que as inovações em empresas de serviço são em sua maioria incrementais, constituídas de pequenos ajustes, já que nenhum deles citou a criação de algo totalmente novo como inovação na Hotelaria. Os presentes autores atribuíram isso ao fato de um dos respondentes ter dito que o mercado de Florianópolis ainda era muito fechado e resistente a inovações. Ou ainda, ao fato de essa resistência estar, nos próprios gestores, que não conseguem visualizar uma forma de inovar totalmente nova, ou ainda por dependerem de diretores e próprios donos dos hotéis, que precisam estar abertos a mudanças, para que os gestores se sintam motivados a pensar de forma criativa e encarar as mudanças que provém de um processo inovador.

Além disso, outro fator que pareceu fazer com que fosse mais difícil perceber a inovação na Hotelaria como algo totalmente novo, ou seja, inovação de produto (serviço) ou inovação de ruptura, seriam as características que descrevem um serviço (intangibilidade, inseparabilidade, heterogeneidade e perecibilidade), principalmente do que diz respeito a sua intangibilidade descrita por Hoffman e Bateson (2003), que diz respeito ao fato de serviços serem desempenhos ou ações, e não objetos, ou seja, não podem ser tocados. O fato de o serviço não ser algo físico e palpável, demanda mais criatividade por parte dos gestores para inovar em algo totalmente novo.

Os gestores do Hotel Porto da Ilha demonstraram ainda ter clareza sobre a importância da inovação para lidar com a concorrência e satisfazer o cliente em suas necessidades, fazendo que a empresa continuasse competitiva no mercado. Os gestores pareceram realmente entender que a hospitalidade pressupunha servir, e que a inovação na Hotelaria poderia ser uma estratégia para tal. 
Os gestores entenderam também que ser inovador depende de características e atitudes da própria pessoa, como buscar conhecimento, estar atualizado, buscar novidades no mercado e saber colocar ideias em práticas. E as organizações podem, a partir do momento que conhecerem a opinião dos gestores, fomentar estas atitudes.

Acredita-se que a pesquisa pode servir de referencial para aqueles gestores que têm anseio por aumentar seus conhecimentos sobre inovação, conhecer seus diferentes tipos e tentar balizar suas práticas para inovações de processo ou ainda de ruptura.

Por fim, chama-se atenção ao fato deste estudo ser uma tentativa de entender e aprofundar o estudo do processo da inovação em serviços. Espera-se que o estudo possa atingir diretores e donos de hotel, que entendem a importância da inovação e valorizam esse processo para a manutenção de um negócio seguro e próspero, e que a partir do estudo tenham interesse em saber o que os gestores de suas organizações pensam sobre inovação, como forma de incentivá-los a trabalhar de forma criativa.

Ressalta-se que o estudo é apenas um recorte da realidade da Hoteleira em Florianópolis, não podendo ser considerado uma evidência do setor no Estado ou no país; para isso, estudos multicasos podem ser realizados com o objetivo de conhecer e comparar diversas realidades sendo possível assim fazer uma generalização.

\section{REFERÊNCIAS}

BENI, M. C. Análise Estrutural do Turismo. 7. ed. São Paulo: SENAC, 2002.

CARDELLINO, P.; FINCH, E. Evidence of systematic approaches to innovation in facilities management. Journal of Facilities Management. London v. 4, n. 3, p. 150166, 2006.

CHRISTENSEN, C. The innovator's dilemma. New York: Harper Business, 2000.

DAMASIO, J. dos S. Qualidade percebida em serviços de hotelaria familiar de Florianópolis: um estudo de caso no Porto da Ilha Hotel. 242 p. Dissertação (Mestrado em Administração) - Universidade do Estado de Santa Catarina, Florianópolis, 2014.

DUARTE, V. V. Administração de sistemas hoteleiros: conceitos básicos. 2. ed. São Paulo: Editora Senac São Paulo, 2003.

ESCAURIAZA, M. J.; SUBIRANA, J. T.; TORRES, X. T. Innovación en Servicios. Fundició Cotec - Collecció Estudis 19, Madri, p 1-20, 2011. 
FINE, C. Mercados em evolução contínua: conquistando vantagem competitiva num mundo em constante mutação. Rio de Janeiro: Campus, 1999.

GADREY, J.; GALLOUJ, F.; WEINSTEIN, O. New modes of innovation: how services benefit industry. International Journal of Service Industry Management. Bradford, v. 6, n. 3, p.4, 1994.

GONZÁLES, O.; GALLEGO, P. A.; GARCÍA-ZAMORA, E. Emprendedorismo y orientación al mercado como precursoras de la innovación: Papel del tamaño empresarial. In: CONGRESO NACIONAL DA ACEDE, 19., 2009, Toledo, Espanha, Artigos... Toledo: Asociación Científica de Economía y Derección de la Empresa. 2009.

GRAEML, A. R. A construção do conhecimento sobre inovação em serviços. In: BERNARDES, R. C.; ANDREASSI, T. (Org.) Inovação em serviços intensivos em conhecimento. São Paulo: Saraiva, 2007.

GIL, A. C. Como elaborar projetos de pesquisa. 3. ed. São Paulo: Atlas, 1991.

GODOY, A. S. Refletindo sobre critérios de qualidade da pesquisa qualitativa. Revista Eletrônica de Gestão Organizacional, v. 3, n. 2, p. 81-89, 2005.

GORNI, P. M.; DREHER, M. T.; MACHADO, D. D. P. N. Inovação em serviços turísticos: a percepção desse processo em agências de viagens. Revista Acadêmica do Observatório de Inovação do Turismo, v. 4, n. 1, art. 1, p. 1-14, 2009.

HAUKNES, J., Services in innovation, innovation in services, SI4S Synthesis Paper, European Commission, Targeted Socio-Economic Research Programme, 1998.

HOFFMAN, K. D.; BATESON, J. E. G. Princípios de marketing de serviços. São Paulo: Thonson Learning, 2003.

IBGE. Produto interno bruto dos municípios. Disponível em: <http://www.ibge.gov.br/home/estatistica/economia/pibmunicipios/2004_2008/pibmuni c2004_2008.pdf>. Acesso em: 7/07/2014.

KLEMENT, C. F. F. Inovação em serviços: estudo de casos em uma organização da indústria hoteleira brasileira. 132 p. Tese (Doutorado) - Faculdade de Economia, Administração e Contabilidade, Universidade de São Paulo, São Paulo, 2007.

MTUR. Sistema Brasileiro de Classificação de meios de hospedagem. Disponível em: $\quad<$ http://www.classificacao.turismo.gov.br/MTUR-classificacao/mtursite/Entenda?tipo=1>. Acesso em: 20/04/2014.

MTUR. Portaria $\mathbf{n}^{\mathbf{0}}$ 100, de 16 de Junho de 2011. Disponível em: <http://www.turismo.gov.br/legislacao/?p=175>. Acesso em: 24/06/2014. 
PORTAL EDUCAÇÃO. Inovação na Hotelaria. Disponível em: <http://www.portaleducacao.com.br/Artigo/Imprimir/25117>. Acesso em: 25/07/2014.

PORTO DA ILHA. Disponível em: 〈http://www.portodailha.com.br>. Acesso em: $15 / 05 / 2014$.

POWERS, T.; BARROWS, C. W. Administração no setor de hospitalidade: turismo, hotelaria e restaurante. São Paulo: Atlas, 2004.

SANTOS, F. M. Análise histórico-espacial do setor hoteleiro no núcleo urbano central de Florianópolis. Dissertação (Mestrado) - UNIVALI, Balneário Camboriú, 2005 .

SCHUMPETER, J. A. Teoria do desenvolvimento econômico. 2. ed. São Paulo: Nova Cultural, 1985.

SILVEIRA, G. C. Avaliação do potencial da estrutura organizacional da Cerâmica Portobello para o desenvolvimento da criatividade. 204 p. Dissertação (Mestrado em Administração) - Universidade Federal de Santa Catarina, Florianópolis, 2004.

SHOSTACK, G. How to design a service. European Journal of Marketing, v. 16, p. 49-63, 1982.

SUNDBO, J; GALLOUJ, F. Innovation in services. SI4S Synthesis Paper, n. 2, 1998.

VERGARA, S. C. Gestão de pessoas. 2. ed. São Paulo: Atlas, 2000.

ZHUANG, L. Bridging the gap between technology and business strategy: a pilot study on the innovation process. Management Decision, v. 33, n. 8, p. 13-21, 1995.

Recebido em: 02-11-2014.

Aprovado em: 02-12-2014. 